\title{
Impact of mHealth Chronic Disease Management on Treatment Adherence and Patient Outcomes: A Systematic Review
}

Saee Hamine ${ }^{1}$, MSc; Emily Gerth-Guyette ${ }^{2}$, MPA; Dunia Faulx², MPH; Beverly B Green ${ }^{3}$, MD, MPH; Amy Sarah Ginsburg $^{2}$, MD, MPH

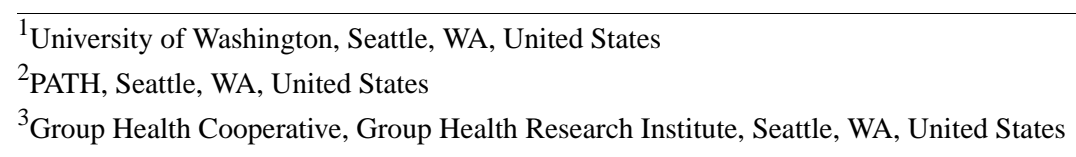

Corresponding Author:

Emily Gerth-Guyette, MPA

PATH

2201 Westlake Ave \#200

Seattle, WA, 98121

United States

Phone: 12062853500

Fax: 12062856619

Email: egerthguyette@path.org

\section{Abstract}

Background: Adherence to chronic disease management is critical to achieving improved health outcomes, quality of life, and cost-effective health care. As the burden of chronic diseases continues to grow globally, so does the impact of non-adherence. Mobile technologies are increasingly being used in health care and public health practice (mHealth) for patient communication, monitoring, and education, and to facilitate adherence to chronic diseases management.

Objective: We conducted a systematic review of the literature to evaluate the effectiveness of mHealth in supporting the adherence of patients to chronic diseases management ("mAdherence"), and the usability, feasibility, and acceptability of mAdherence tools and platforms in chronic disease management among patients and health care providers.

Methods: We searched PubMed, Embase, and EBSCO databases for studies that assessed the role of mAdherence in chronic disease management of diabetes mellitus, cardiovascular disease, and chronic lung diseases from 1980 through May 2014. Outcomes of interest included effect of mHealth on patient adherence to chronic diseases management, disease-specific clinical outcomes after intervention, and the usability, feasibility, and acceptability of mAdherence tools and platforms in chronic disease management among target end-users.

Results: In all, 107 articles met all inclusion criteria. Short message service was the most commonly used mAdherence tool in $40.2 \%$ (43/107) of studies. Usability, feasibility, and acceptability or patient preferences for mAdherence interventions were assessed in $57.9 \%(62 / 107)$ of studies and found to be generally high. A total of 27 studies employed randomized controlled trial (RCT) methods to assess impact on adherence behaviors, and significant improvements were observed in 15 of those studies (56\%). Of the 41 RCTs that measured effects on disease-specific clinical outcomes, significant improvements between groups were reported in 16 studies $(39 \%)$.

Conclusions: There is potential for mHealth tools to better facilitate adherence to chronic disease management, but the evidence supporting its current effectiveness is mixed. Further research should focus on understanding and improving how mHealth tools can overcome specific barriers to adherence.

(J Med Internet Res 2015;17(2):e52) doi: 10.2196/jmir.3951

\section{KEYWORDS}

telemedicine; mHealth; mobile health; patient compliance; patient adherence; chronic disease; diabetes mellitus; cardiovascular diseases; lung diseases 


\section{Introduction}

Chronic diseases are the most common causes of death and disability worldwide [1]. Chronic disease management often requires a long-term care plan. Adherence to chronic disease management is critical to achieving improved health outcomes, quality of life, and cost-effective health care [1]. A World Health Organization review of adherence behaviors noted that, "increasing adherence may have a greater effect on health than improvements in specific medical therapy" [2]. With an average adherence rate of only $50 \%$ among patients with chronic diseases, non-adherence is a serious challenge to chronic disease management [3]. The extent of non-adherence is even higher in developing countries [3-5]. The long-term nature and frequent need for continuous monitoring in chronic disease management gave rise to early developments in telehealth and telemonitoring. These innovations, which seek to improve chronic disease management and prevent death and disability, are improved by ongoing technological advancements.

One such advancement is mHealth-health care and public health practice supported by mobile devices [6]. Close to three-quarters of the world's population has access to a mobile phone with increasingly powerful technical capacities [7]. More than 6.9 billion mobile subscriptions were in use as of May 2014, 5.4 billion of which were in developing countries [8]. Based on their popularity, availability, portability, and technological capacity, mobile phones and mHealth have enormous potential to impact chronic disease management around the globe. A World Health Organization survey of global mHealth initiatives published in 2011 reported a "groundswell" of activity in both developed and developing countries [6]. Mobile technologies such as phones and wireless monitoring devices are increasingly being used in health care and public health practice for communication, data collection, patient monitoring, and education, and to facilitate adherence to chronic disease management [6]. mHealth devices can improve service delivery and impact patient outcomes [6]. Sensors and context-awareness features allow for individualization and real-time information submission delivery. Moreover, the strong attachment people have to mobile phones and the tendency to carry them everywhere, opens up opportunities for continuous symptom monitoring and connecting patients with providers outside of health care facilities.

While the growing popularity of mHealth is evident, its impact is not. The reported impact of mHealth interventions is mixed, with studies showing modest benefits for some clinical diagnosis and management support outcomes $[9,10]$. Studies have shown the positive impact of mHealth on adherence-related behavior among patients with human immunodeficiency virus (HIV) and tuberculosis. For example, short message service (SMS) appointment reminders have led to an increase in attendance among children exposed to or infected with HIV in Cameroon [11]. However, criticism of mHealth includes its implementation through small pilot initiatives that address a single disease or issue in service delivery and lack of globally accepted ways to evaluate effectiveness [7]. Systematic reviews to date are indicative of mHealth's segmented nature, which may include a single technology or a single chronic disease or a specific
mHealth application [12-14]. Another review, focused on the impact of SMS interventions, found that text messaging increased adherence to antiretroviral treatment with reductions in viral load and biochemically verified smoking cessation, yet these effects were "small and of borderline clinical importance" [9]. A more comprehensive Cochrane review assessed the health impact of SMS on any type of long-term illness, but found only four comparative effectiveness trials able to address the impact of mobile services on self-management [14]. Moreover, the literature search did not go past 2009, and we are unaware of any updates.

The impact of these mHealth tools on adherence to treatment regimens may be overlooked, as mHealth promoters are eager to demonstrate their effect on clinical outcomes (eg, morbidity, mortality, and biometric markers of clinical disease). Adherence to treatment, and specifically adherence to treatment of chronic diseases, is a critical link that connects the promise of mHealth to the ultimate goal of improved clinical outcomes. This review builds the evidence base of mHealth by updating previous reviews and assessing a broad range of outcomes from usability to impact on health outcomes. This enables us to consider mHealth tools at all stages of development and gauge the effectiveness of mHealth interventions across a range of technologies and chronic diseases, many of which have overlapping treatment regimens and require similar adherence behaviors. This review aims to evaluate the effectiveness of mHealth in supporting adherence of patients to chronic disease management—which we call "mAdherence" — and the usability, feasibility, and acceptability of mAdherence tools and platforms for chronic disease management.

\section{Methods}

\section{Overview}

We undertook a systematic review of mHealth interventions used to facilitate adherence to chronic disease management. The chronic diseases included are diabetes mellitus (DM), cardiovascular diseases (CVDs), and chronic lung diseases (CLDs). CVDs include hypertension (HTN), coronary artery disease, and congestive heart failure. CLDs include asthma and chronic obstructive pulmonary disease (COPD). These chronic diseases were chosen based on their high global burden [15]. Our definition of mHealth was adopted from the Global Observatory for eHealth definition: "medical and public health practice supported by mobile devices" [6]. We use the term "mAdherence" to refer to any use of mHealth tools by patients and health care providers to improve adherence to chronic disease management. Given the comprehensive nature of chronic disease management, this review goes beyond defining adherence as compliance with a treatment regimen and includes a wide range of interventions, such as medication reminders, symptom monitoring, educational tools, and facilitated patient-provider communication [16].

Employing Boolean phrases, we searched PubMed, Embase, and EBSCO databases for studies that assessed the role of mAdherence in chronic disease management of DM, CVD, and CLD. MeSH terms (Medical Subject Headings) and advanced search-builder features were used for the PubMed searches. 
Emtree terms using the explosion function to extend the search were employed to build a multi-term query along with advanced searches in Embase. Finally, CINAHL, PsychInfo, and PsychArticles were included for searches in the EBSCO database. EndnoteWeb was used for sorting and removal of duplicates. We searched databases for articles published from 1980 through May 2014.

\section{Inclusion and Exclusion Criteria}

We included original research published in peer-reviewed journals that evaluated mHealth tools for effect on patient adherence to chronic disease management, disease-specific clinical outcomes, and usability, feasibility, and acceptability features. mHealth interventions aimed at improving chronic disease management were included even if the research did not address adherence specifically. Usability, feasibility, and acceptability studies that focused on the design and development stages of mAdherence interventions were included as a necessary precursor to future evaluation. Studies that measured adherence included outcomes such as use of the mHealth tool for monitoring and reporting symptoms, compliance with medication regimens, and engagement in healthy behaviors. Studies that focused on clinical measures, such as hemoglobin A1c (HbA1c) or blood pressure (BP), were included, as improved clinical outcomes are the eventual goal of improving adherence and often indicate adherence to chronic disease management indirectly. Allowing for flexibility in the outcomes measured was necessary for an inclusive view of mAdherence technologies in all stages of design, development, and evaluation.

mHealth included any mobile device or service, such as mobile phones, SMS, smartphones, personal digital assistants, and devices that work on wireless technology or Bluetooth-compatible devices. These devices and services allowed patients to monitor their health, access health information, and communicate with their health care provider without requiring a wired connection to the Internet. We included interventions delivered using a Web-based platform only if it was specified that the patient accessed the service via a mobile phone or other mobile device. It was required that patients be the primary users of the mAdherence tools.

Only articles reporting that the mAdherence intervention was designed for secondary prevention targeting chronic disease patients were included. We excluded reports of studies on primary prevention among healthy or at-risk groups. We also excluded articles regarding interventions that were not tested in a sample population with clearly described methods and results. In addition, review articles, editorials, commentaries, dissertations, poster presentations, abstracts only, proposals for future studies, study protocols, and descriptive articles describing new tools but not testing them in a sample population were excluded. Publication language was restricted to English only.

\section{Data Extraction and Analysis}

Publications were initially screened for potential inclusion based on simultaneous review of title and abstract by two reviewers. Any discrepancies were resolved by consensus among the researchers. Information including objectives, types of mobile technology used, role of mAdherence tools in chronic diseases management, setting, study sample characteristics, outcomes measured, and results reported were extracted using Microsoft Excel. Studies were organized for analysis based on the primary objective of the study and the key outcomes measured. Outcomes were organized into qualitative usability, feasibility, and acceptability of the mAdherence tool or platform among target end-users, the effect of mAdherence on patient adherence to chronic diseases management, and disease-specific clinical outcomes of the mAdherence intervention. We performed descriptive analyses of the data and summarized the findings from these studies, with emphasis on statistical results reported in randomized controlled trials (RCTs). We highlighted differences between groups when these results were available.

\section{Results}

\section{Summary}

In all, 638 articles were retrieved in full text and assessed for eligibility. Based on the search criteria, 531 articles were excluded. Of the excluded articles, many did not meet the study design criteria $(n=225)$ or did not align with the definition of mHealth used here $(n=199)$. A total of 60 articles were beyond the scope of the chronic diseases considered in this review, and 116 articles did not include any adherence component. An additional 20 articles were excluded because they were not available in English or a full text version was not obtainable despite all reasonable attempts. A total of 107 articles met all inclusion criteria. Figure 1 illustrates the selection process. 
Figure 1. Study selection process.

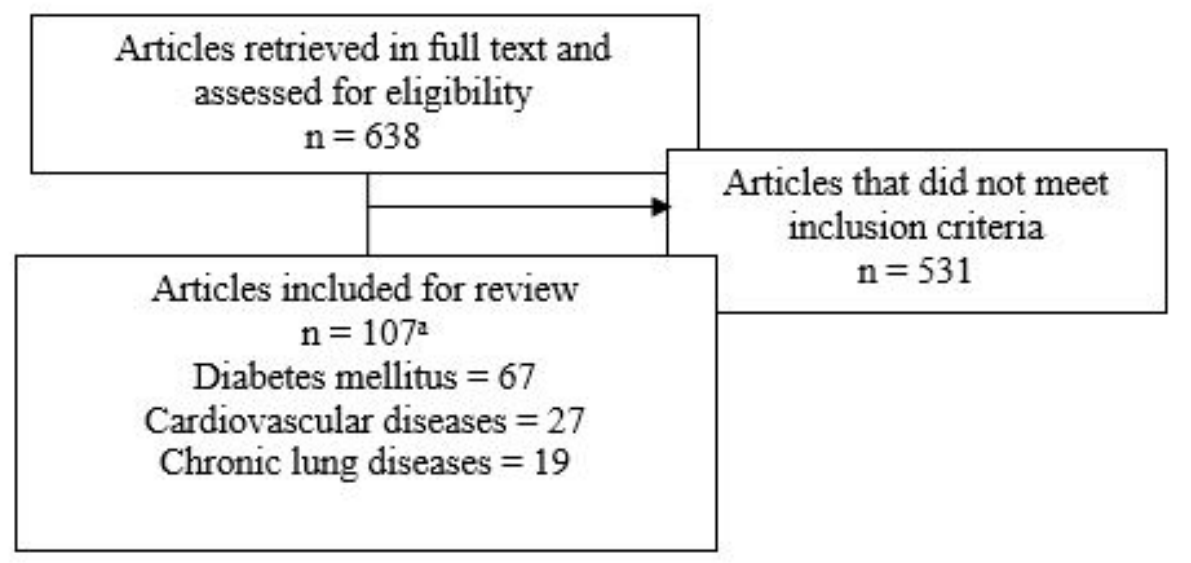

${ }^{2} \mathrm{Six}$ articles studied both diabetes mellitus and cardiovascular diseases.

\section{Study Characteristics}

Publication years ranged from 2003 to 2014, with an overall increase in articles published more recently (Figure 2). None of the studies published before 2003 met our inclusion criteria. A total of $34.6 \%(37 / 107)$ of studies were conducted in the United States, followed by $10.3 \%(11 / 107)$ in the United Kingdom, and $10.3 \%$ (11/107) in South Korea (Figure 3). Of note, only one study was conducted in India, one in China, and one in Africa.
RCTs $(46.7 \%, 50 / 107)$ that assessed the differences between $\mathrm{mAdherence} \mathrm{tools} \mathrm{or} \mathrm{between} \mathrm{an} \mathrm{mAdherence} \mathrm{tool} \mathrm{and} \mathrm{standard}$ care were the most common study design. DM (62.6\%, 67/107) interventions were the most common, followed by CVD $(25.2 \%$, 27/107) and CLD (17.8\%, 19/107) interventions (Table 1). Six studies targeted both DM and CVDs and were included in both categories. Study durations ranged from just a few hours to 18 months, with an average duration of around 6 months. Sample sizes also varied widely, ranging from 4 to 710 participants.

Table 1. Study designs by chronic disease $(\mathrm{n}=107)$.

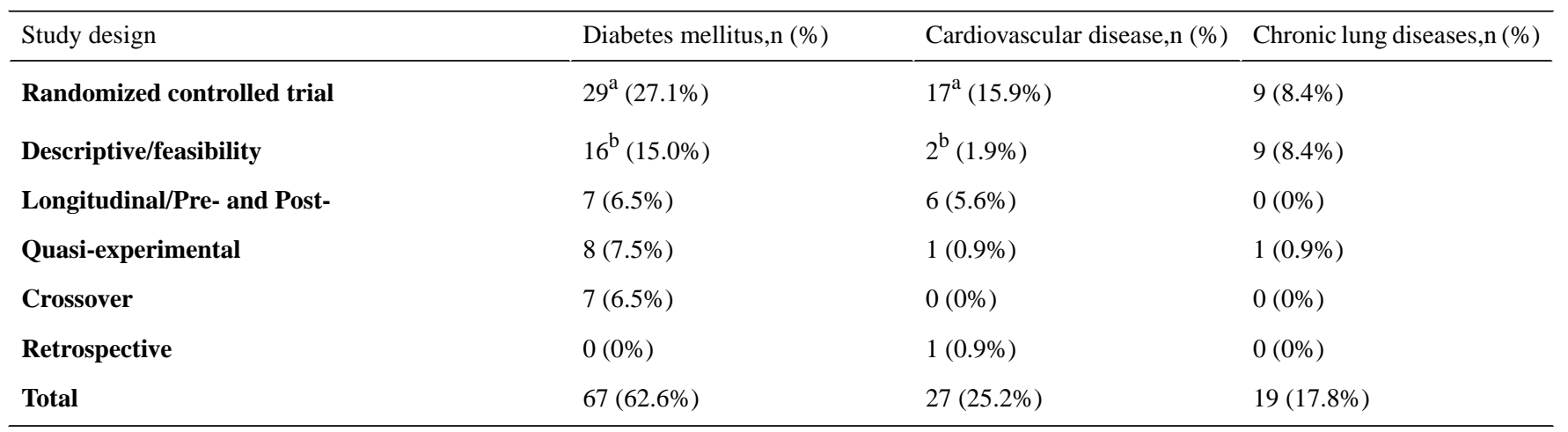

${ }^{a}$ Five articles included here considered both cardiovascular disease and diabetes mellitus.

${ }^{\mathrm{b}}$ One article included here considered both cardiovascular disease and diabetes mellitus. 
Figure 2. mAdherence studies published over time.

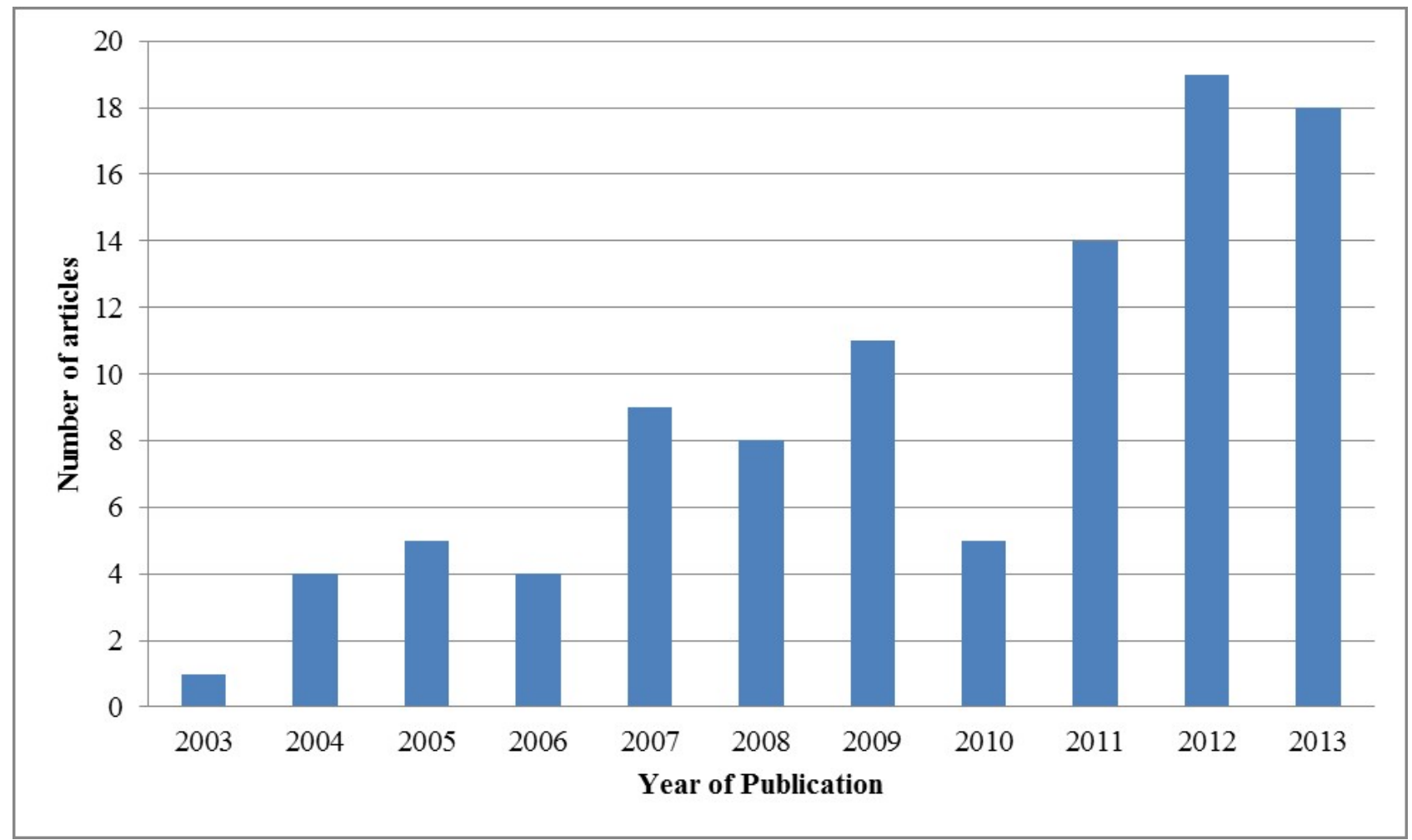

Figure 3. mAdherence studies published by country.

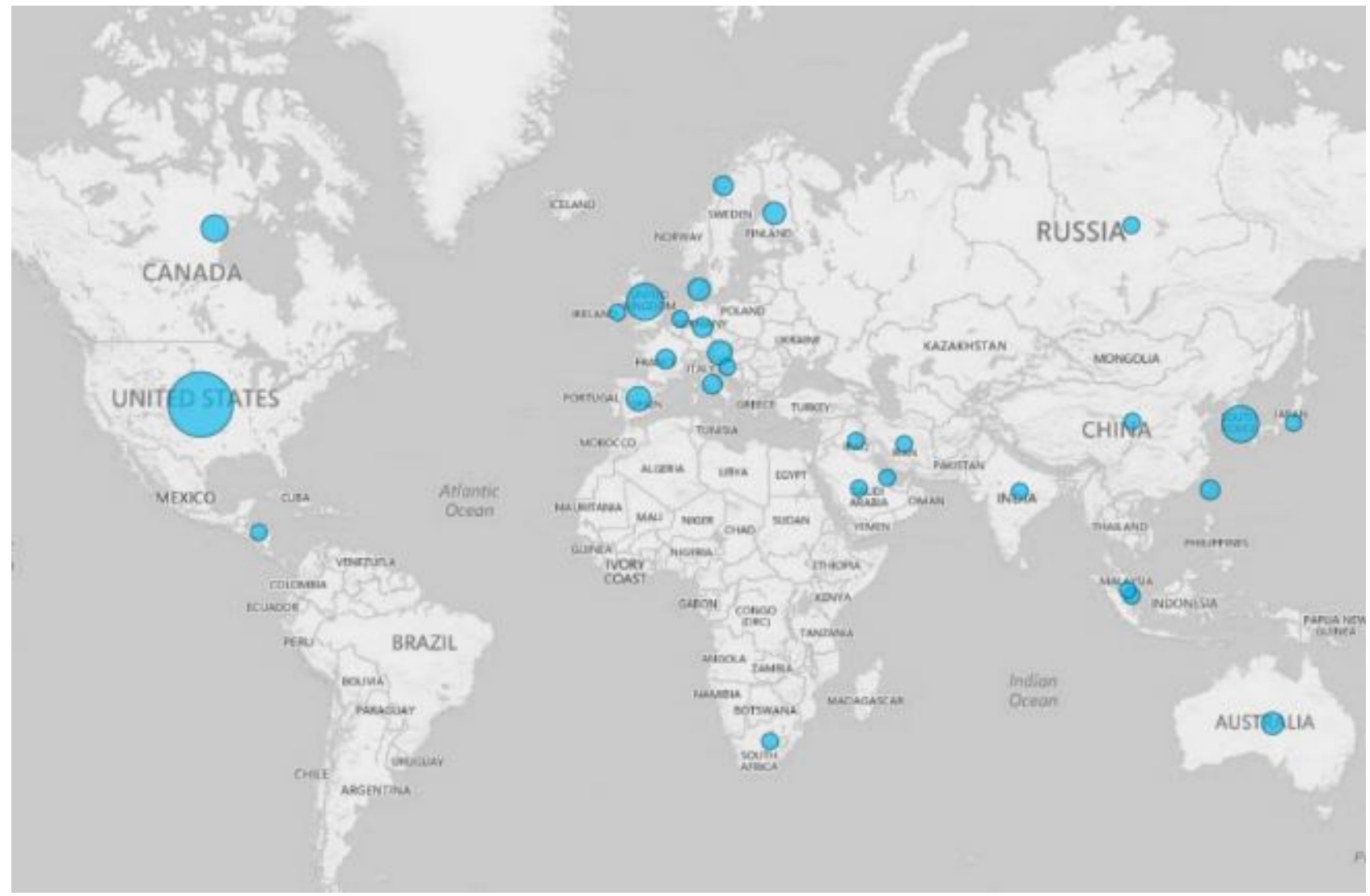

\section{mAdherence Users}

Several of the studies focused on the use of mAdherence tools by vulnerable, hard-to-reach, or otherwise high-risk patient populations. This included elderly patients, members of minority ethnic and racial groups, and low-income adults. The characteristics of the target user group was often the impetus for the development of the mAdherence tool. For example, researchers noted that travel to a health care provider's office can be difficult for older patients, and that mAdherence tools 
could lessen that burden [17]. Some studies also considered specific design considerations, such as larger device screens, that could make mAdherence tools easier to use by older adults [18]. In general, mAdherence tools targeting low-income, elderly, and minority groups were found to be usable with high satisfaction ratings [17-21]. In most of these interventions, mobile phones or other devices were either provided to users or considered a requirement for study participation. In a study that did not provide a mobile device to participants, access to mobile phones was noted to be a significant barrier [22].

In a study addressing the lack of knowledge in designing mHealth interventions for low-income and racial or ethnic minorities with DM, the authors noted that very little is known about decisions made in the mHealth design process for these patient populations [23]. An iterative design process involving systems and content development and multiple stages of user experience testing was recommended as a template for future mAdherence tools aimed at similar patient populations [23]. Ultimately, it appears that diverse individuals can use mAdherence tools as long as the tools are tailored to the needs of the population and sufficient training and support are provided $[18,23]$.

\section{Mobile Tools Used in mAdherence}

For the purposes of this analysis, we classified mAdherence tools and platforms into four main categories: SMS; phone plus software or application; phone plus specific instrument (medical device connected to phone via a cord); or phone plus wireless or Bluetooth-compatible device (Figure 4). SMS interventions require the least sophisticated hardware and can be used to transmit simple information from patients on their personal phones. Specialized software or applications including patient portals, management systems, and other complex communication platforms require only a commercially available smartphone. Here, patients generally need to manually input information. Wireless or Bluetooth-compatible refers to medical devices used by patients that transmit information wirelessly to mobile phones and computers for viewing by both patients and health care providers. Phones plus a specific instrument require additional medical hardware usually not available on a commercial smartphone.

SMS $(40.2 \%, 43 / 107)$ was the most commonly used tool and the primary platform. SMS facilitated patient-provider communication, medication reminders, and data collection and exchange on disease-specific measurements, as well as delivered patient education and motivation [24-26]. It is important to note that while SMS was often a feature of more complex patient-provider communication platforms, the $40.2 \%$ (43/107) of studies here used SMS exclusively. The next most common mAdherence tool was specialized software or a smartphone app, used in $23.4 \%$ (25/107) of studies. Use of specialized software applications was high among patients with DM. For example, mAdherence software could be installed on the patient's mobile phone to help remember to check symptoms, maintain a food diary, or connect patients to DM educators in real time.

A wireless or Bluetooth-compatible device was used in $17.8 \%$ $(19 / 107)$ of studies and a specific instrument connected to a phone, such as a blood glucose (BG) meter, was used in $13.1 \%$ (14/107) of studies. These mAdherence programs focused mainly on a combination of devices such as an electrocardiogram, BP monitor, and weighing machine with a wireless or Bluetooth interface, thus facilitating transfer of data automatically without requiring the patient to manually submit the data [27]. Data could then be reviewed by the health care provider and used to recommend an appropriate course of action. In some systems, automated criteria-based alerts were created, initiating an immediate response from the provider when measurements fell outside the target range [27,28]. CVD mAdherence programs also allowed for supervised cardiac rehabilitation by a remote monitoring system for those unable to access hospital-based programs [19].

Figure 4. Types of mobile tools used in mAdherence.

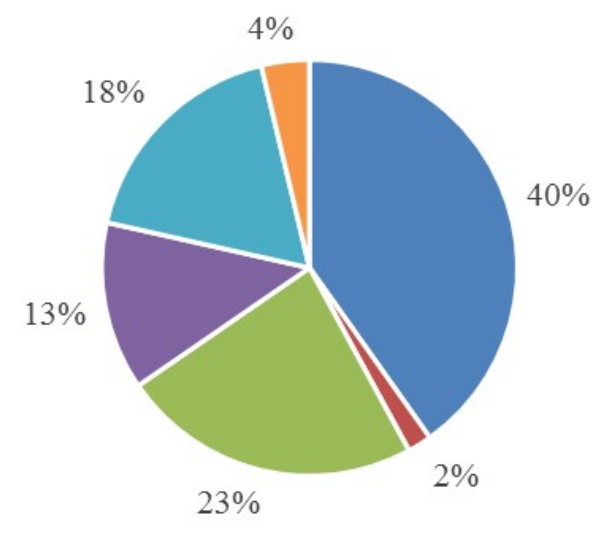

\section{Study Outcomes and Indicators}

Multiple outcome measures were used to evaluate mAdherence depending on stated study objectives. For the purposes of this
- SMS

- Video messaging

- Phone plus software or application

- Phone plus specific instrument

- Wireless or Bluetooth-compatible device

- Other: pager, interactive voice response, electronic medication monitoring, non-phone portable devices analysis, the outcomes are organized into three categories: usability, feasibility, and acceptability of the mAdherence tool; effect of the mAdherence intervention on adherence to chronic disease management; and effect of the mAdherence intervention 
on disease-specific outcomes. In all, 62 studies (57.9\%, 62/107) assessed usability, feasibility, and acceptability using qualitative methods and compiled usage data. These data ranged from patient satisfaction to cost-effectiveness estimations as well as timing and frequency of engagement with mobile tools and platforms. A total of 73 studies $(68.2 \%, 73 / 107)$ evaluated the effect of an mAdherence intervention on adherence to chronic disease management, including medication adherence, engagement in healthy behaviors, frequency of symptom monitoring, and gains in knowledge and perceived self-efficacy. A total of 60 studies $(56.1 \%, 60 / 107)$ assessed the effect of mAdherence on disease-specific clinical outcomes. Common clinical outcomes for $\mathrm{DM}$ included $\mathrm{HbA1c}$, frequency of hypoglycemic events, and changes in insulin dosage. CVD measurements included changes in BP, lipid profile, and other biomarkers, as well as CVD risk profile. Examples of improved management of CLDs included indications of lung function, use of nebulizers, and exercise tests.

\section{Usability, Feasibility, and Acceptability}

A total of $57.9 \%(62 / 107)$ of studies assessed usability, feasibility, and acceptability or patient preferences for mAdherence interventions. In general, the studies found mAdherence tools and platforms to be usable, feasible, acceptable, and appreciated among users. The majority of studies focused on the patient as the end-user of mAdherence, though some also looked at acceptability from the provider perspective. Features of mAdherence tools such as automated reminders, text messages with educational and motivational content, healthy living challenges, and wireless transmission of data contributed to increased self-care awareness and knowledge about chronic diseases [29-33]. mAdherence tools facilitated better management and improved patient confidence to monitor chronic diseases, making the patients feel in control and strengthening coping mechanisms [34]. Patients expressed feeling reassured, with decreased anxiety, knowing that their health symptoms were regularly monitored [28]. Often, having the mAdherence system as an interface between the patient and the provider was perceived as less burdensome and judgmental compared to face-to-face contact, particularly in situations in which the patients were not fully adherent to the recommended treatment [34].

The feasibility and acceptability of mAdherence tools were evaluated across diverse patient populations, including low-income, bilingual populations, and otherwise difficult-to-reach patients. The majority of participants included in these studies reported good comprehension and satisfaction [20,21,35-37]. For example, both adolescent patients with DM and their parents perceived that using an mAdherence system increased the adolescent's independence and confidence in disease management $[25,37,38]$. Adolescent patients gave high ratings regarding the usefulness and feasibility of mAdherence systems to help them remember to take their medications and be attentive to their symptoms [21,25,26,36,39]. Parents of adolescent patients appreciated the decreased burden of reminding their children to perform required testing and self-care and noted decreased parent-adolescent conflict [25]. Among elderly populations, mAdherence was accepted and considered especially useful among older patients living alone and/or with memory issues [17]. One study found that the use of the mHealth DM tool studied was conditioned by gender [40]. Men and women were motivated by different priorities in their dietary self-efficacy and wanted different information, and the authors urge that gender be taken into account for future mHealth interventions. Physician providers also favored an mAdherence system that provided patient data and supported clinical decision-making [28].

Though mAdherence tools were generally accepted, patients and providers documented a number of negative elements and perceptions. Patients' primary concerns included dependence on professional supervision, unnecessary medicalization, and undue anxiety if technology failed [30,34]. Difficulty in understanding and using the technology were reported, including technical issues such as too many menus to navigate and small buttons on the mobile phone [31]. Some patients who had not used smartphones before found them frustrating to use [32]. Among providers, concerns included the amount of time and effort required to review data and respond in time [41]. While studies confirmed that mAdherence tools are feasible in low-income populations, cost remains a barrier to more widespread use [22]. Factors such as the cost of implementing the system, increased clinical workload and workflow, maintaining up-to-date records, and concerns about being supervised and depending too much on technology were some of the main concerns regarding implementation of mAdherence interventions [28,30,34].

\section{Impact on Adherence}

Only the subset of studies that employed a randomized comparison between two groups was included in this analysis. Descriptive studies and studies that did not involve a comparison group were excluded, as their diverse designs and methods prevented meaningful comparisons. Of the 27 RCTs that measured the effect of mAdherence on adherence behaviors, a statistically significant change or difference between groups $(P<.05$ to $P<.001)$ was observed in 15 studies $(56 \%)$ (Table 2$)$. Multimedia Appendix 1 provides an overview of the methods and outcomes of these studies [18,33,35,37,42-64].

Two studies $(4 \%, 2 / 27)$ found mixed results and $10(37 \%, 10 / 27)$ showed no difference. Use of daily SMS reminders for medication intake with and without real-time medication monitoring showed significant improvements in patient adherence rates [42-46]. Text messaging tailored to counteract negative beliefs about asthma and education to overcome external barriers were associated with improved adherence to medication $[43,47]$. One study demonstrated the dual benefits of both better access to patient data and mobile coaching [65]. For adolescent patients with DM, employing automated, scheduled SMS programs providing motivational support was associated with improved adherence, understanding, and attention to DM care $[45,48]$. SMS notifications were particularly effective in increasing adherence to medication after a cardiac event $[49,50]$. Notably in one study, the use of an electronic blister pack with SMS communication significantly improved adherence to DM medication only and not to other types of medication [51]. 
Table 2. Effectiveness of mAdherence on adherence outcomes.

\begin{tabular}{lllll}
\hline & Significant effect,n (\%) & No significant effect,n (\%) & Mixed results,n (\%) & Total \\
\hline Diabetes mellitus & $7^{\mathrm{a}}(50 \%)$ & $5(36 \%)$ & $2(14 \%)$ & $14^{\mathrm{a}}$ \\
Cardiovascular disease & $5^{\mathrm{a}}(83 \%)$ & $1(17 \%)$ & $0(0 \%)$ & $6^{\mathrm{a}}$ \\
Chronic lung diseases & $4(50 \%)$ & $4(50 \%)$ & $0(0 \%)$ & 8 \\
Total adherence outcome studies & $15(56 \%)$ & $10(37 \%)$ & $2(7 \%)$ & 27 \\
\hline
\end{tabular}

${ }^{\mathrm{a} O n e}$ article is included here in both cardiovascular disease and diabetes mellitus.

\section{Impact on Clinical Outcomes}

In all, 41 studies $(38.3 \%, 41 / 107)$ evaluated the impact of mAdherence tools on clinical outcomes (Table 3). Of the RCTs that measured the effect of mAdherence on disease-specific clinical outcomes, significant differences between groups $(P<.05$ to $P<.001)$ were reported in 16 studies $(39 \%, 16 / 41)$. No significant differences were found in 14 studies $(34 \%, 14 / 41)$, and mixed results were observed in $11(27 \%)$. Multimedia Appendix 2 provides an overview of the methods and outcomes

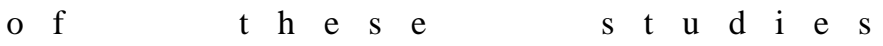
[18,23,27,30,33,35,39,42,43,45,46,48,49,52-55,57-61,65-83].

A total of 26 of the RCT interventions were related to improving DM management and care. Significant improvements in DM-specific clinical outcomes such as BG, HbA1c, and two-hour postprandial BG were reported in 11 studies (42\%, 11/26). Both adolescents and elderly patients receiving messages with tailored instructions on DM care experienced statistically significant improvements in their HbA1c levels $[18,31,45,46,66,67,84]$. A total of 13 studies evaluated mAdherence tools for CVDs. Significant improvements in clinical outcomes such as BP, weight, and lipid profile were reported in 7 studies $(54 \%, 7 / 13)$. In one study, SMS enabled interactive monitoring so that the provider could set reminders for patients with HTN, collect data, and schedule visits for treatment adjustments [68]. This resulted in $77 \%$ of patients achieving goal BP levels. Pairing data transfer with a criteria-based alarm system that alerted and initiated contact from the physician was associated with a significant decrease in systolic BP [27]. Significant reduction in BP was also observed among HTN patients using an electronic salt sensor and mobile phone [69]. Patients with risk factors for coronary artery disease showed significant improvement after using an mHealth system consisting of an automatic sphygmomanometer, BG and lipid meter, and mobile phone [70]. Four interventions were designed to improve outcomes for patients with both DM and CVD and half these studies showed significant improvements in clinical outcomes, including HbA1c and BP control [71-74]. Mixed results in CLD clinical outcomes, mainly lung function parameters, were reported in $3(50 \%)$ of 6 RCTs that evaluated mAdherence for CLD, and the other 3 RCTs found non-significant results. SMS interventions improved cough symptoms and sleep quality [52]. Among COPD patients, use of mobile phones installed with music software to record respiratory symptoms during their exercise training showed a significant increase in the walking distance of the incremental shuttle walk test compared to the control group [53].

Table 3. Effectiveness of mAdherence on clinical outcomes $(n=41)$.

\begin{tabular}{|c|c|c|c|c|}
\hline & Significant effect,n (\%) & $\begin{array}{l}\text { No significant effect,n } \\
(\%)\end{array}$ & $\begin{array}{l}\text { Mixed results,n } \\
(\%)\end{array}$ & Total \\
\hline Diabetes mellitus & $11^{\mathrm{a}}(42 \%)$ & $9(35 \%)$ & $6^{\mathrm{a}}(23 \%)$ & $26^{\mathrm{b}}$ \\
\hline Cardiovascular disease & $7^{\mathrm{a}}(54 \%)$ & $2(15 \%)$ & $4^{\mathrm{a}}(31 \%)$ & $13^{\mathrm{b}}$ \\
\hline Chronic lung diseases & $0(0 \%)$ & $3(50 \%)$ & $3(50 \%)$ & 6 \\
\hline Total clinical outcome studies & $16(39 \%)$ & $14(34 \%)$ & $11(27 \%)$ & 41 \\
\hline
\end{tabular}

${ }^{\mathrm{a}}$ Two articles are included here in both cardiovascular disease and diabetes mellitus.

${ }^{\mathrm{b}}$ Four articles are included here in both cardiovascular disease and diabetes mellitus.

\section{Discussion}

\section{Principal Findings}

The evidence presented here indicates that while the potential of mAdherence tools is high, their implementation and execution is mixed. In all, 50 of the studies employed RCT methodology, and of those, just more than half demonstrated significant effects on adherence $(56 \%)$ and less than half $(40 \%)$ on clinical outcomes. SMS is the mHealth tool most widely, frequently, and successfully used to facilitate adherence to chronic disease management. Able to be used by those with little technology experience or familiarity, SMS can be made available relatively inexpensively on any mobile phone, and can be automated, personalized, and easily integrated into existing health systems. However, it is highly operator dependent, relying on the active engagement of patients and providers to monitor symptoms and exchange information, and there is clearly room for improvement. The freedom and portability of mobile devices combined with the advanced capacity to facilitate two-way communication and collect and analyze data for a real-time response offer enormous potential to patients and providers. 
The potential complexity of today's mAdherence tools and the mixed evidence in support of their effectiveness call for a renewed focus on understanding the connection between patient experience, adherence, and health outcomes.

More than half of the studies employed qualitative methods that yielded rich data that can be used to better understand how and why mAdherence tools impact adherence behaviors and clinical outcomes. User feedback can inform hypotheses that can then be tested. There is a growing understanding of barriers to adherence and ways to overcome them. mAdherence tools should be conceived, designed, developed, and evaluated with these barriers in mind. Research that seeks to understand how and why mAdherence works will deliver on the broader promise of mHealth. Future mHealth tools will be able to draw on the knowledge generated when discrete hypotheses around the relative importance of, for example, patient-provider communication, optimal user-interfaces, or targeted motivational messages are tested. This could lead to better mAdherence tools that deliver improved health outcomes.

This review found that the usability, feasibility, and acceptability of mHealth tools for chronic disease management adherence were generally high among both patients and providers. Innovative mAherence tools could unintentionally increase health disparities due to unequal access to technology. Vulnerable, hard-to-reach, or otherwise high-risk patient populations were the target audiences for several mAdherence interventions. There is a clear recognition that mHealth tools have the potential to impact patients who are less inclined to engage traditional health services. mAdherence offers a way to address barriers to care and to reduce health disparities. There is also some recognition that unequal access to, use of, and knowledge of information and communication technology can influence the uptake and use of mHealth tools. These inequalities and the needs of the target user group should be taken into consideration early in the design and development of the mAdherence tool. However, none of the studies included in this review addressed systematic differences in usability between diverse patient groups. Future research can be designed to better understand these differences and to encourage the development of mAdherence tools that address the needs of diverse patient groups.

Of note, few studies take seriously the issue of cost. In many of the small pilot studies, expensive devices or vouchers were given to study participants. When implemented at scale, interventions that use patients' existing mobile devices rather than relying on gifted devices will go further toward explaining feasibility and improving adherence. Though currently concentrated in the developed world, pockets of mAdherence innovations are expanding around the globe. As developing countries work to address the burden of chronic disease, they may look to the potential of mHealth to lessen that burden. Part of that potential is to reduce costs and expand outreach. More mAdherence studies from resource-limited settings, especially in Africa and Asia, are needed. Rigorous cost-effectiveness analyses will be necessary to demonstrate not only the health impact but also the value of investing in these innovations now.

Besides cost, language, and literacy barriers, availability and connectivity issues are also potential barriers to consider. Perhaps most critically, if adherence to chronic disease management is not encouraged and actively practiced, it is very unlikely that mAdherence will be successful. mHealth tools are communication platforms and delivery mechanisms, not solutions in and of themselves. mAdherence will only work where there is already a functioning adherence program in place. Our review demonstrates that mAdherence can play a key role in translating mHealth technologies into better health outcomes. This role is becoming more explicit as mHealth research moves forward.

\section{Limitations}

There are limitations to this systematic review. It is not a meta-analysis, and we did not weigh the quality of evidence or study design against reported results. We also did not include non-English literature, and some of the studies included as few as four participants. The diversity of study objectives, designs, and outcomes made clear comparisons difficult and the quality of evidence was variable.

Our review expands the current evidence base regarding the impact of mHealth on chronic disease management adherence by including common chronic diseases, extending the definition of mHealth beyond SMS to other types of mobile and wireless communication, and by assessing both self-management outcomes and the nascent literature regarding mHealth feasibility, usability, and acceptability.

\section{Conclusion}

mAdherence is a potential high-impact tool to improve health outcomes among those living with chronic diseases through enhanced chronic disease management adherence. Further evaluation of mAdherence tools will be critical, especially research that informs how these tools overcome barriers to chronic disease management. More innovation, optimization, and high-quality research in mAdherence has the potential to transform the promise of mHealth technology into the reality of improved health care delivery and outcomes.

\section{Acknowledgments}

We would like to acknowledge Julianne Erin Williams for her efforts in data extraction required for analysis, and Terry Jankowski (University of Washington librarian) for her guidance in developing search queries and navigating various databases for systematic search of articles.

\section{Conflicts of Interest}

None declared. 


\section{Multimedia Appendix 1}

Randomized controlled trials that measured impact of mHealth tools on patient adherence $(\mathrm{n}=27)$.

[PDF File (Adobe PDF File), 101KB-Multimedia Appendix 1]

\section{Multimedia Appendix 2}

Randomized controlled trials that measured impact of mHealth tools on patient clinical outcomes $(n=41)$.

[PDF File (Adobe PDF File), 136KB-Multimedia Appendix 2]

\section{References}

1. Viswanathan M, Golin CE, Jones CD, Ashok M, Blalock SJ, Wines RC, et al. Interventions to improve adherence to self-administered medications for chronic diseases in the United States: a systematic review. Ann Intern Med 2012 Dec 4;157(11):785-795. [doi: 10.7326/0003-4819-157-11-201212040-00538] [Medline: 22964778]

2. Brown MT, Bussell JK. Medication adherence: WHO cares? Mayo Clin Proc 2011 Apr;86(4):304-314 [FREE Full text] [doi: 10.4065/mcp.2010.0575] [Medline: 21389250]

3. Burkhart PV, Sabaté E. Adherence to long-term therapies: evidence for action. J Nurs Scholarsh 2003;35(3):207. [Medline: 14562485]

4. Choudhry NK, Dugani S, Shrank WH, Polinski JM, Stark CE, Gupta R, et al. Despite increased use and sales of statins in India, per capita prescription rates remain far below high-income countries. Health Aff (Millwood) 2014 Feb;33(2):273-282. [doi: 10.1377/hlthaff.2013.0388] [Medline: 24493771]

5. Beaglehole R, Epping-Jordan J, Patel V, Chopra M, Ebrahim S, Kidd M, et al. Improving the prevention and management of chronic disease in low-income and middle-income countries: a priority for primary health care. The Lancet 2008 Sep 13;372(9642):940-949. [doi: 10.1016/S0140-6736(08)61404-X] [Medline: 18790317]

6. World Health Organization. Second Global Survey on eHealth (Global Observatory for eHealth). Geneva: World Health Organization; 2011. mHealth: New horizons for health through mobile technologies URL: http://www.who.int/goe/ publications/goe mhealth web.pdf [accessed 2015-02-16] [WebCite Cache ID 6WOo8btQp]

7. Mobile phone access reaches three quarters of planet's population.: World Bank; 2012 Jul 17. URL: http://www. worldbank.org/en/news/press-release/2012/07/17/mobile-phone-access-reaches-three-quarters-planets-population [accessed 2014-09-17] [WebCite Cache ID 6SfJLVISK]

8. International Telecommunications Union. Global Mobile Statistics 2014 Part A: Mobile subscribers; handset market share; mobile operators. 2014 May. Mobile subscribers worldwide URL: $\underline{\text { http://mobiforge.com/research-analysis/ }}$ global-mobile-statistics-2014-part-a-mobile-subscribers-handset-market-share-mobile-operators?mT [accessed 2014-10-13] [WebCite Cache ID 6TIuCrYTQ]

9. Free C, Phillips G, Watson L, Galli L, Felix L, Edwards P, et al. The effectiveness of mobile-health technologies to improve health care service delivery processes: a systematic review and meta-analysis. PLoS Med 2013;10(1):e1001363 [FREE Full text] [doi: 10.1371/journal.pmed.1001363] [Medline: 23458994]

10. Tomlinson M, Rotheram-Borus MJ, Swartz L, Tsai AC. Scaling up mHealth: where is the evidence? PLoS Med 2013;10(2):e1001382 [FREE Full text] [doi: 10.1371/journal.pmed.1001382] [Medline: 23424286]

11. Bigna JJR, Noubiap JJN, Kouanfack C, Plottel CS, Koulla-Shiro S. Effect of mobile phone reminders on follow-up medical care of children exposed to or infected with HIV in Cameroon (MORE CARE): a multicentre, single-blind, factorial, randomised controlled trial. The Lancet Infectious Diseases 2014 Jul;14(7):600-608. [doi: 10.1016/S1473-3099(14)70741-8] [Medline: 24932893]

12. van Velthoven MH, Brusamento S, Majeed A, Car J. Scope and effectiveness of mobile phone messaging for HIV/AIDS care: a systematic review. Psychol Health Med 2013;18(2):182-202. [doi: 10.1080/13548506.2012.701310] [Medline: 22788357]

13. Nglazi MD, Bekker LG, Wood R, Hussey GD, Wiysonge CS. Mobile phone text messaging for promoting adherence to anti-tuberculosis treatment: a systematic review protocol. Syst Rev 2013;2(1):6 [FREE Full text] [doi: 10.1186/2046-4053-2-6] [Medline: 23324135]

14. de Jongh T, Gurol-Urganci I, Vodopivec-Jamsek V, Car J, Atun R. Mobile phone messaging for facilitating self-management of long-term illnesses. Cochrane Database Syst Rev 2012;12:CD007459. [doi: 10.1002/14651858.CD007459.pub2] [Medline: 23235644]

15. Lozano R, Naghavi M, Foreman K, Lim S, Shibuya K, Aboyans V, et al. Global and regional mortality from 235 causes of death for 20 age groups in 1990 and 2010: a systematic analysis for the Global Burden of Disease Study 2010. Lancet 2012 Dec 15;380(9859):2095-2128. [doi: 10.1016/S0140-6736(12)61728-0] [Medline: 23245604]

16. Norris SL, Glasgow RE, Engelgau MM, Os'Connor PJ, McCulloch D. Chronic disease management. Disease Management \& Health Outcomes 2003 Aug;11(8):477-488. [doi: 10.2165/00115677-200311080-00001]

17. Durso SC, Wendel I, Letzt AM, Lefkowitz J, Kaseman DF, Seifert RF. Older adults using cellular telephones for diabetes management: a pilot study. Medsurg Nurs 2003 Oct;12(5):313-317. [Medline: 14608688] 
18. Lim S, Kang SM, Shin H, Lee HJ, Won Yoon J, Yu SH, et al. Improved glycemic control without hypoglycemia in elderly diabetic patients using the ubiquitous healthcare service, a new medical information system. Diabetes Care 2011 Feb;34(2):308-313 [FREE Full text] [doi: 10.2337/dc10-1447] [Medline: 21270188]

19. Fischer HH, Moore SL, Ginosar D, Davidson AJ, Rice-Peterson CM, Durfee MJ, et al. Care by cell phone: text messaging for chronic disease management. Am J Manag Care 2012 Feb;18(2):e42-e47 [FREE Full text] [Medline: 22435883]

20. Dick JJ, Nundy S, Solomon MC, Bishop KN, Chin MH, Peek ME. Feasibility and usability of a text message-based program for diabetes self-management in an urban African-American population. J Diabetes Sci Technol 2011 Sep;5(5):1246-1254 [FREE Full text] [Medline: 22027326]

21. MacDonell K, Gibson-Scipio W, Lam P, Naar-King S, Chen X. Text messaging to measure asthma medication use and symptoms in urban African American emerging adults: a feasibility study. J Asthma 2012 Dec;49(10):1092-1096. [doi: 10.3109/02770903.2012.733993] [Medline: 23106138]

22. Nundy S, Razi RR, Dick JJ, Smith B, Mayo A, O'Connor A, et al. A text messaging intervention to improve heart failure self-management after hospital discharge in a largely African-American population: before-after study. J Med Internet Res 2013 Mar 11;15(3):e53 [FREE Full text] [doi: 10.2196/jmir.2317] [Medline: 23478028]

23. Osborn CY, Mulvaney SA. Development and feasibility of a text messaging and interactive voice response intervention for low-income, diverse adults with type 2 diabetes mellitus. J Diabetes Sci Technol 2013 May;7(3):612-622 [FREE Full text] [Medline: 23759393]

24. Carroll AE, DiMeglio LA, Stein S, Marrero DG. Using a cell phone-based glucose monitoring system for adolescent diabetes management. Diabetes Educ 2011;37(1):59-66. [doi: 10.1177/0145721710387163] [Medline: 21106908]

25. Franklin VL, Greene A, Waller A, Greene SA, Pagliari C. Patients' engagement with "Sweet Talk" - a text messaging support system for young people with diabetes. J Med Internet Res 2008;10(2):e20 [FREE Full text] [doi: 10.2196/jmir.962] [Medline: 18653444$]$

26. Mulvaney SA, Anders S, Smith AK, Pittel EJ, Johnson KB. A pilot test of a tailored mobile and web-based diabetes messaging system for adolescents. J Telemed Telecare 2012 Mar;18(2):115-118 [FREE Full text] [doi: 10.1258/jtt.2011.111006] [Medline: 22383802]

27. Seto E, Leonard KJ, Cafazzo JA, Barnsley J, Masino C, Ross HJ. Mobile phone-based telemonitoring for heart failure management: a randomized controlled trial. J Med Internet Res 2012 Feb 16;14(1):e31 [FREE Full text] [doi: 10.2196/jmir.1909] [Medline: 22356799]

28. Worringham C, Rojek A, Stewart I. Development and feasibility of a smartphone, ECG and GPS based system for remotely monitoring exercise in cardiac rehabilitation. PLoS One 2011 Feb 09;6(2):e14669 [FREE Full text] [doi: 10.1371/journal.pone.0014669] [Medline: 21347403]

29. Pinnock H, Slack R, Pagliari C, Price D, Sheikh A. Understanding the potential role of mobile phone-based monitoring on asthma self-management: qualitative study. Clin Exp Allergy 2007 May;37(5):794-802. [doi: 10.1111/j.1365-2222.2007.02708.x] [Medline: 17456228]

30. Faridi Z, Liberti L, Shuval K, Northrup V, Ali A, Katz D. Evaluating the impact of mobile telephone technology on type 2 diabetic patients' self-management: the NICHE pilot study. J Eval Clin Pract 2008 Jun;14(3):465-469. [doi: 10.1111/j.1365-2753.2007.00881.x] [Medline: 18373577$]$

31. Lyles CR, Harris LT, Le T, Flowers J, Tufano J, Britt D, et al. Qualitative evaluation of a mobile phone and web-based collaborative care intervention for patients with type 2 diabetes. Diabetes Technol Ther 2011 May;13(5):563-569. [doi: 10.1089/dia.2010.0200] [Medline: 21406018]

32. Ryan D, Cobern W, Wheeler J, Price D, Tarassenko L. Mobile phone technology in the management of asthma. J Telemed Telecare 2005;11 Supp 1:43-46. [doi: 10.1258/1357633054461714] [Medline: $\underline{16035991]}$

33. Ryan D, Price D, Musgrave SD, Malhotra S, Lee AJ, Ayansina D, et al. Clinical and cost effectiveness of mobile phone supported self monitoring of asthma: multicentre randomised controlled trial. BMJ 2012;344:e1756 [FRE Full text] [Medline: 22446569]

34. Anhøj J, Møldrup C. Feasibility of collecting diary data from asthma patients through mobile phones and SMS (short message service): response rate analysis and focus group evaluation from a pilot study. J Med Internet Res 2004 Dec 2;6(4):e42 [FREE Full text] [doi: 10.2196/jmir.6.4.e42] [Medline: 15631966]

35. Arora S, Peters AL, Burner E, Lam CN, Menchine M. Trial to examine text message-based mHealth in emergency department patients with diabetes (TExT-MED): a randomized controlled trial. Ann Emerg Med 2014 Jun;63(6):745-54.e6. [doi: 10.1016/j.annemergmed.2013.10.012] [Medline: 24225332]

36. Britto MT, Munafo JK, Schoettker PJ, Vockell AL, Wimberg JA, Yi MS. Pilot and feasibility test of adolescent-controlled text messaging reminders. Clin Pediatr (Phila) 2012 Feb;51(2):114-121. [doi: 10.1177/0009922811412950] [Medline: 22019792]

37. Seid M, D'Amico EJ, Varni JW, Munafo JK, Britto MT, Kercsmar CM, et al. The in vivo adherence intervention for at risk adolescents with asthma: report of a randomized pilot trial. J Pediatr Psychol 2012 May;37(4):390-403 [FREE Full text] [doi: 10.1093/jpepsy/jsr107] [Medline: 22167121] 
38. Gammon D, Arsand E, Walseth OA, Andersson N, Jenssen M, Taylor T. Parent-child interaction using a mobile and wireless system for blood glucose monitoring. J Med Internet Res 2005 Nov 21;7(5):e57 [FREE Full text] [doi: 10.2196/jmir.7.5.e57] [Medline: 16403721]

39. Neumann CL, Menne J, Rieken EM, Fischer N, Weber MH, Haller H, et al. Blood pressure telemonitoring is useful to achieve blood pressure control in inadequately treated patients with arterial hypertension. J Hum Hypertens 2011 Dec 13;25(12):732-738. [doi: 10.1038/jhh.2010.119] [Medline: 21228822]

40. Burner E, Menchine M, Taylor E, Arora S. Gender differences in diabetes self-management: a mixed-methods analysis of a mobile health intervention for inner-city Latino patients. J Diabetes Sci Technol 2013 Jan;7(1):111-118 [FREE Full text] [Medline: 23439166]

41. Halkoaho A, Kavilo M, Pietilä A. Information technology supporting diabetes sel-care: a pilot study. Eur Diab Nursing 2007 Jan 25;4(1):14-17. [doi: 10.1002/edn.70]

42. Strandbygaard U, Thomsen SF, Backer V. A daily SMS reminder increases adherence to asthma treatment: a three-month follow-up study. Respir Med 2010 Feb;104(2):166-171 [FREE Full text] [doi: 10.1016/j.rmed.2009.10.003] [Medline: 19854632]

43. Lv Y, Zhao H, Liang Z, Dong H, Liu L, Zhang D, et al. A mobile phone short message service improves perceived control of asthma: a randomized controlled trial. Telemed J E Health 2012;18(6):420-426. [doi: 10.1089/tmj.2011.0218] [Medline: 22667695]

44. Vervloet M, van Dijk L, Santen-Reestman J, van Vlijmen B, van Wingerden P, Bouvy ML, et al. SMS reminders improve adherence to oral medication in type 2 diabetes patients who are real time electronically monitored. Int J Med Inform 2012 Sep;81(9):594-604. [doi: 10.1016/j.ijmedinf.2012.05.005] [Medline: 22652012]

45. Franklin VL, Waller A, Pagliari C, Greene SA. A randomized controlled trial of Sweet Talk, a text-messaging system to support young people with diabetes. Diabet Med 2006 Dec;23(12):1332-1338. [doi: 10.1111/j.1464-5491.2006.01989.x] [Medline: 17116184]

46. Hanauer DA, Wentzell K, Laffel N, Laffel LM. Computerized Automated Reminder Diabetes System (CARDS): e-mail and SMS cell phone text messaging reminders to support diabetes management. Diabetes Technol Ther 2009 Feb;11(2):99-106. [doi: 10.1089/dia.2008.0022] [Medline: 19848576 ]

47. Petrie KJ, Perry K, Broadbent E, Weinman J. A text message programme designed to modify patients' illness and treatment beliefs improves self-reported adherence to asthma preventer medication. Br J Health Psychol 2012 Feb;17(1):74-84. [doi: 10.1111/j.2044-8287.2011.02033.x] [Medline: 22107110]

48. Kumar VS, Wentzell KJ, Mikkelsen T, Pentland A, Laffel LM. The DAILY (Daily Automated Intensive Log for Youth) trial: a wireless, portable system to improve adherence and glycemic control in youth with diabetes. Diabetes Technol Ther 2004 Aug;6(4):445-453. [doi: 10.1089/1520915041705893] [Medline: 15320998]

49. Quilici J, Fugon L, Beguin S, Morange PE, Bonnet JL, Alessi MC, et al. Effect of motivational mobile phone short message service on aspirin adherence after coronary stenting for acute coronary syndrome. Int J Cardiol 2013 Sep 20;168(1):568-569. [doi: 10.1016/j.ijcard.2013.01.252] [Medline: 23462636]

50. Khonsari S, Subramanian P, Chinna K, Latif LA, Ling LW, Gholami O. Effect of a reminder system using an automated short message service on medication adherence following acute coronary syndrome. Eur J Cardiovasc Nurs 2014 Feb 2:[Epub ahead of print]. [doi: 10.1177/1474515114521910] [Medline: 24491349]

51. Brath H, Morak J, Kästenbauer T, Modre-Osprian R, Strohner-Kästenbauer H, Schwarz M, et al. Mobile health (mHealth) based medication adherence measurement - a pilot trial using electronic blisters in diabetes patients. Br J Clin Pharmacol 2013 Sep;76 Suppl 1:47-55. [doi: 10.1111/bcp.12184] [Medline: 24007452]

52. Ostojic V, Cvoriscec B, Ostojic SB, Reznikoff D, Stipic-Markovic A, Tudjman Z. Improving asthma control through telemedicine: a study of short-message service. Telemed J E Health 2005 Feb;11(1):28-35. [doi: 10.1089/tmj.2005.11.28] [Medline: 15785218]

53. Liu WT, Wang CH, Lin HC, Lin SM, Lee KY, Lo YL, et al. Efficacy of a cell phone-based exercise programme for COPD. Eur Respir J 2008 Sep;32(3):651-659 [FREE Full text] [doi: 10.1183/09031936.00104407] [Medline: 18508824]

54. Benhamou PY, Melki V, Boizel R, Perreal F, Quesada JL, Bessieres-Lacombe S, et al. One-year efficacy and safety of Web-based follow-up using cellular phone in type 1 diabetic patients under insulin pump therapy: the PumpNet study. Diabetes Metab 2007 Jun;33(3):220-226 [FREE Full text] [doi: 10.1016/j.diabet.2007.01.002] [Medline: 17395516]

55. Cho J, Lee H, Lim D, Kwon H, Yoon K. Mobile communication using a mobile phone with a glucometer for glucose control in Type 2 patients with diabetes: as effective as an Internet-based glucose monitoring system. J Telemed Telecare 2009;15(2):77-82. [doi: 10.1258/jtt.2008.080412] [Medline: 19246607]

56. DeSalvo DJ, Keith-Hynes P, Peyser T, Place J, Caswell K, Wilson DM, et al. Remote glucose monitoring in cAMP setting reduces the risk of prolonged nocturnal hypoglycemia. Diabetes Technol Ther 2014 Jan;16(1):1-7. [doi: 10.1089/dia.2013.0139] [Medline: 24168317]

57. Kim C, Kim H, Nam J, Cho M, Park J, Kang E, et al. Internet diabetic patient management using a short messaging service automatically produced by a knowledge matrix system. Diabetes Care 2007 Nov;30(11):2857-2858. [doi: 10.2337/dc06-2464] [Medline: 17682122$]$ 
58. Kirwan M, Vandelanotte C, Fenning A, Duncan MJ. Diabetes self-management smartphone application for adults with type 1 diabetes: randomized controlled trial. J Med Internet Res 2013;15(11):e235 [FREE Full text] [doi: 10.2196/jmir.2588] [Medline: 24225149]

59. Shetty AS, Chamukuttan S, Nanditha A, Raj RK, Ramachandran A. Reinforcement of adherence to prescription recommendations in Asian Indian diabetes patients using short message service (SMS)--a pilot study. J Assoc Physicians India 2011 Nov;59:711-714. [Medline: 22616337]

60. Zolfaghari M, Mousavifar SA, Pedram S, Haghani H. The impact of nurse short message services and telephone follow-ups on diabetic adherence: which one is more effective? J Clin Nurs 2012 Jul;21(13-14):1922-1931. [doi: 10.1111/j.1365-2702.2011.03951.x] [Medline: 22239205]

61. Carrasco MP, Salvador CH, Sagredo PG, Márquez-Montes J, González de Mingo MA, Fragua JA, et al. Impact of patient-general practitioner short-messages-based interaction on the control of hypertension in a follow-up service for low-to-medium risk hypertensive patients: a randomized controlled trial. IEEE Trans Inf Technol Biomed 2008 Nov;12(6):780-791. [doi: 10.1109/TITB.2008.926429] [Medline: 19000959]

62. Park LG, Howie-Esquivel J, Whooley MA, Dracup K. Psychosocial factors and medication adherence among patients with coronary heart disease: A text messaging intervention. Eur J Cardiovasc Nurs 2014 May 21:-. [doi: 10.1177/1474515114537024] [Medline: 24853566]

63. Park LG, Howie-Esquivel J, Chung ML, Dracup K. A text messaging intervention to promote medication adherence for patients with coronary heart disease: a randomized controlled trial. Patient Educ Couns 2014 Feb;94(2):261-268. [doi: 10.1016/j.pec.2013.10.027] [Medline: 24321403]

64. Nguyen HQ, Gill DP, Wolpin S, Steele BG, Benditt JO. Pilot study of a cell phone-based exercise persistence intervention post-rehabilitation for COPD. Int J Chron Obstruct Pulmon Dis 2009;4:301-313 [FREE Full text] [Medline: 19750190]

65. Quinn CC, Shardell MD, Terrin ML, Barr EA, Ballew SH, Gruber-Baldini AL. Cluster-randomized trial of a mobile phone personalized behavioral intervention for blood glucose control. Diabetes Care 2011 Sep;34(9):1934-1942 [FREE Full text] [doi: 10.2337/dc11-0366] [Medline: 21788632]

66. Harno K, Kauppinen-Mäkelin R, Syrjäläinen J. Managing diabetes care using an integrated regional e-health approach. J Telemed Telecare 2006;12 Suppl 1:13-15. [doi: 10.1258/135763306777978380] [Medline: $\underline{16884565]}$

67. Kim HS, Jeong HS. A nurse short message service by cellular phone in type-2 diabetic patients for six months. J Clin Nurs 2007 Jun;16(6):1082-1087. [doi: 10.1111/j.1365-2702.2007.01698.x] [Medline: 17518883]

68. Kiselev AR, Gridnev VI, Shvartz VA, Posnenkova OM, Dovgalevsky PY. Active ambulatory care management supported by short message services and mobile phone technology in patients with arterial hypertension. J Am Soc Hypertens 2012;6(5):346-355. [doi: 10.1016/j.jash.2012.08.001] [Medline: 22995803]

69. Morikawa N, Yamasue K, Tochikubo O, Mizushima S. Effect of salt reduction intervention program using an electronic salt sensor and cellular phone on blood pressure among hypertensive workers. Clin Exp Hypertens 2011;33(4):216-222. [doi: 10.3109/10641963.2011.583966] [Medline: 21699447]

70. Blasco A, Carmona M, Fernández-Lozano I, Salvador CH, Pascual M, Sagredo PG, et al. Evaluation of a telemedicine service for the secondary prevention of coronary artery disease. J Cardiopulm Rehabil Prev 2012;32(1):25-31. [doi: 10.1097/HCR.0b013e3182343aa7] [Medline: 22113368]

71. Istepanian RS, Zitouni K, Harry D, Moutosammy N, Sungoor A, Tang B, et al. Evaluation of a mobile phone telemonitoring system for glycaemic control in patients with diabetes. J Telemed Telecare 2009;15(3):125-128. [doi: 10.1258/jtt.2009.003006] [Medline: 19364893]

72. Earle KA, Istepanian RS, Zitouni K, Sungoor A, Tang B. Mobile telemonitoring for achieving tighter targets of blood pressure control in patients with complicated diabetes: a pilot study. Diabetes Technol Ther 2010 Jul;12(7):575-579. [doi: 10.1089/dia.2009.0090] [Medline: 20597833]

73. Yoon KH, Kim HS. A short message service by cellular phone in type 2 diabetic patients for 12 months. Diabetes Res Clin Pract 2008 Feb;79(2):256-261. [doi: 10.1016/j.diabres.2007.09.007] [Medline: 17988756]

74. Logan AG, Irvine MJ, McIsaac WJ, Tisler A, Rossos PG, Easty A, et al. Effect of home blood pressure telemonitoring with self-care support on uncontrolled systolic hypertension in diabetics. Hypertension 2012 Jul;60(1):51-57 [FREE Full text] [doi: 10.1161/HYPERTENSIONAHA.111.188409] [Medline: 22615116]

75. Bell AM, Fonda SJ, Walker MS, Schmidt V, Vigersky RA. Mobile phone-based video messages for diabetes self-care support. J Diabetes Sci Technol 2012 Mar;6(2):310-319 [FREE Full text] [Medline: 22538140]

76. Leu MG, Norris TE, Hummel J, Isaac M, Brogan MW. A randomized, controlled trial of an automated wireless messaging system for diabetes. Diabetes Technol Ther 2005 Oct;7(5):710-720 discussion 719-20. [doi: 10.1089/dia.2005.7.710] [Medline: 16241873$]$

77. Nagrebetsky A, Larsen M, Craven A, Turner J, McRobert N, Murray E, et al. Stepwise self-titration of oral glucose-lowering medication using a mobile telephone-based telehealth platform in type 2 diabetes: a feasibility trial in primary care. $\mathrm{J}$ Diabetes Sci Technol 2013;7(1):123-134 [FREE Full text] [Medline: 23439168]

78. Quinn CC, Clough SS, Minor JM, Lender D, Okafor MC, Gruber-Baldini A. WellDoc mobile diabetes management randomized controlled trial: change in clinical and behavioral outcomes and patient and physician satisfaction. Diabetes Technol Ther 2008 Jun;10(3):160-168. [doi: 10.1089/dia.2008.0283] [Medline: 18473689] 
79. Rossi MC, Nicolucci A, Di Bartolo P, Bruttomesso D, Girelli A, Ampudia FJ, et al. Diabetes Interactive Diary: a new telemedicine system enabling flexible diet and insulin therapy while improving quality of life: an open-label, international, multicenter, randomized study. Diabetes Care 2010 Jan;33(1):109-115 [FREE Full text] [doi: 10.2337/dc09-1327] [Medline: 19808926]

80. Koehler F, Winkler S, Schieber M, Sechtem U, Stangl K, Böhm M, Telemedical Interventional Monitoring in Heart Failure Investigators. Impact of remote telemedical management on mortality and hospitalizations in ambulatory patients with chronic heart failure: the telemedical interventional monitoring in heart failure study. Circulation 2011 May 3;123(17):1873-1880 [FREE Full text] [doi: 10.1161/CIRCULATIONAHA.111.018473] [Medline: 21444883]

81. Madsen LB, Kirkegaard P, Pedersen EB. Blood pressure control during telemonitoring of home blood pressure. A randomized controlled trial during 6 months. Blood Press 2008;17(2):78-86. [doi: 10.1080/08037050801915468] [Medline: 18568696]

82. Prabhakaran L, Chee WY, Chua KC, Abisheganaden J, Wong WM. The use of text messaging to improve asthma control: a pilot study using the mobile phone short messaging service (SMS). J Telemed Telecare 2010;16(5):286-290. [doi: 10.1258/jtt.2010.090809] [Medline: 20576744]

83. Istepanian RS, Sungoor A, Earle KA. Technical and compliance considerations for mobile health self-monitoring of glucose and blood pressure for patients with diabetes. Conf Proc IEEE Eng Med Biol Soc 2009;2009:5130-5133. [doi: 10.1109/IEMBS.2009.5334580] [Medline: 19965037]

84. Yoo HJ, Park MS, Kim TN, Yang SJ, Cho GJ, Hwang TG, et al. A ubiquitous chronic disease care system using cellular phones and the internet. Diabet Med 2009 Jun;26(6):628-635. [doi: 10.1111/j.1464-5491.2009.02732.x] [Medline: 19538239]

\section{Abbreviations}

2Hpg: two-hour plasma glucose

AACM: active ambulatory care management

ACQ: asthma control questionnaire

ACS: acute coronary syndrome

ACT: asthma control test

AQLQ: asthma-specific quality-of-life questionnaire

baPWV: brachial-ankle pulse wave velocity

BG: blood glucose

BMI: body mass index

BNP: brain natriuretic peptide

BP: blood pressure

CARDS: Computerized Automated Reminder Diabetes System

CDSS: clinical decision support system

CGM: continuous glucose monitoring

CHD: coronary heart disease

CI: confidence interval

CIT: conventional insulin therapy

CLD: chronic lung disease

COPD: chronic obstructive pulmonary disease

CPDS: coach PCP portal with decision support

CPP: coach PCP portal

CRF: cardiovascular risk factors

CVD: cardiovascular disease

DBP: diastolic blood pressure

DID: diabetes interactive diary

DM: diabetes mellitus

ECG: electrocardiogram/electrocardiography

eNO: exhaled nitric oxide

FEV1: forced expiratory volume in one second

HbA1c: hemoglobin A1c

HCP: health care provider

HDL: high-density lipoprotein

HIV: human immunodeficiency virus

HRQL: health-related quality of life

HTN: hypertension

KASE-AQ: knowledge, attitude, and self-efficacy asthma questionnaire

LDL: low-density lipoprotein

LVEF: left ventricular ejection fraction 
MEMS: Medication Event Monitoring System

MeSH: Medical Subject Headings

NICHE: Novel, Interactive Cell-phone Technology for Health Enhancement

PCA: perceived control of asthma

PCAQ-6: six-item PCA questionnaire

PCP: primary care provider

PDA: personal digital assistant

PEF: peak expiratory flow

RCT: randomized controlled trial

RR: risk ratio

RTM: remote telemedical management

RTMM: real-time medication monitoring

SBP: systolic blood pressure

SD: standard deviation

SMBG: self-monitoring of blood glucose

SMS: short message service

TACM: traditional ambulatory care management

TExT-MED: text message-based mHealth program to improve diabetes management

TM: telemonitoring

UCDC: ubiquitous chronic disease care

WAP: wireless application protocol

Edited by G Eysenbach; submitted 16.10.14; peer-reviewed by P Gee, G Egger; comments to author 31.12.14; revised version received 21.01.15; accepted 21.01.15; published 24.02.15

Please cite as:

Hamine S, Gerth-Guyette E, Faulx D, Green BB, Ginsburg AS

Impact of mHealth Chronic Disease Management on Treatment Adherence and Patient Outcomes: A Systematic Review

J Med Internet Res 2015;17(2):e52

URL: http://www.jmir.org/2015/2/e52/

doi: $10.2196 /$ jmir.3951

PMID: 25803266

(CSaee Hamine, Emily Gerth-Guyette, Dunia Faulx, Beverly B Green, Amy Sarah Ginsburg. Originally published in the Journal of Medical Internet Research (http://www.jmir.org), 24.02.2015. This is an open-access article distributed under the terms of the Creative Commons Attribution License (http://creativecommons.org/licenses/by/2.0/), which permits unrestricted use, distribution, and reproduction in any medium, provided the original work, first published in the Journal of Medical Internet Research, is properly cited. The complete bibliographic information, a link to the original publication on http://www.jmir.org/, as well as this copyright and license information must be included. 